\title{
Temperature and Pressure Dependence of Gas Permeation in a Microporous Tröger's Base Polymer
}

\author{
Elsa Lasseuguette ${ }^{1}\left(\mathbb{D}\right.$, Richard Malpass-Evans ${ }^{2}$, Mariolino Carta $\left.{ }^{3}{ }^{(}\right)$, Neil B. McKeown ${ }^{2}$ and \\ Maria-Chiara Ferrari ${ }^{1}$ * \\ 1 School of Engineering, University of Edinburgh, Robert Stevenson Road, Edinburgh EH9 3FB, UK; \\ e.lasseuguette@ed.ac.uk \\ 2 EastChem, School of Chemistry, University of Edinburgh, David Brewster Road, Edinburgh EH9 3FJ, UK; \\ R.Malpass-Evans@ed.ac.uk (R.M.-E.); Neil.McKeown@ed.ac.uk (N.B.M.) \\ 3 Department of Chemistry, College of Science, Grove Building, Singleton Park, Swansea University, Swansea \\ SA2 8PP, UK; mariolino.carta@swansea.ac.uk \\ * Correspondence: m.ferrari@ed.ac.uk; Tel.: +44-131-650-5689
}

Received: 31 October 2018; Accepted: 5 December 2018; Published: 14 December 2018

check for updates

\begin{abstract}
Gas transport properties of PIM-EA( $\left(\mathrm{H}_{2}\right)-\mathrm{TB}$, a microporous Tröger's base polymer, were systematically studied over a range of pressure and temperature. Permeability coefficients of pure $\mathrm{CO}_{2}, \mathrm{~N}_{2}, \mathrm{CH}_{4}$ and $\mathrm{H}_{2}$ were determined for upstream pressures up to 20 bar and temperatures up to $200{ }^{\circ} \mathrm{C}$. PIM-EA( $\left.\mathrm{H}_{2}\right)$-TB exhibited high permeability coefficients in absence of plasticization phenomena. The permeability coefficient of $\mathrm{N}_{2}, \mathrm{CH}_{4}$ and $\mathrm{H}_{2}$ increased with increasing temperature while $\mathrm{CO}_{2}$ permeability decreased with increasing temperature as expected for a glassy polymer. The diffusion and solubility coefficients were also analysed individually and compared with other polymers of intrinsic microporosity. From these results, the activation energies of permeation, diffusion and sorption enthalpies were calculated using an Arrhenius equation.
\end{abstract}

Keywords: microporous polymer; gas permeability; activation energy; $\mathrm{CO}_{2}$ capture

\section{Introduction}

Membranes are one of the most promising technologies to compete with conventional separation processes for gas separations including post- and pre-combustion carbon capture. Studies on the use of polymeric membranes in an Integrated Gasification Combined Cycle (IGCC) power plant [1-3] show their viability and their competitiveness with the currently more developed solvent-based technology. Process simulations [1] have shown an advantage for hydrogen selective materials for this application and new membrane materials are currently under development [3]. The performance of the materials in the relatively harsh conditions of the separation (50 bars and $200{ }^{\circ} \mathrm{C}$ ) needs to be investigated before production can be scaled up [4].

The increase of gas pressure can have a negative impact on membrane performance, due to plasticization effects. For glassy polymers, many gases, such as $\mathrm{O}_{2}, \mathrm{~N}_{2}$ and $\mathrm{H}_{2}$, can permeate through the polymer without modifying the polymer's properties due to their relatively low solubility in the polymer. Therefore, with the pressure's increase, the gas permeability slightly decreases, as expected from the dual sorption-dual mobility model [5]. On the contrary, highly sorbing gases such as $\mathrm{CO}_{2}$ can induce a swelling of the polymer matrix, that is, plasticization, leading to a large increase of the gas permeability with increasing pressure. In addition, the influence of temperature on gas separation performance has been investigated for a large number of polymers. Depending on the polymer, the membrane performance can be improved by an increase of temperature as shown by the Robeson plot in Figure 1. Most polymers, including ultrahigh-free volume polymers such as PTMSP and Teflon 
$\mathrm{AF}$, present higher hydrogen selectivity over $\mathrm{CO}_{2}$ at high temperature. For example, Merkel et al. [6] reported $\mathrm{H}_{2} \mathrm{~S}, \mathrm{CO}_{2}, \mathrm{H}_{2}, \mathrm{~N}_{2}$ and $\mathrm{CO}$ permeation as a function of temperature up to $240{ }^{\circ} \mathrm{C}$. At room temperature, PTMSP appears to be more permeable to the more condensable gases, such as $\mathrm{CO}_{2}$ and $\mathrm{H}_{2} \mathrm{~S}$ than to $\mathrm{H}_{2}$. However, it becomes hydrogen selective at elevated temperatures.

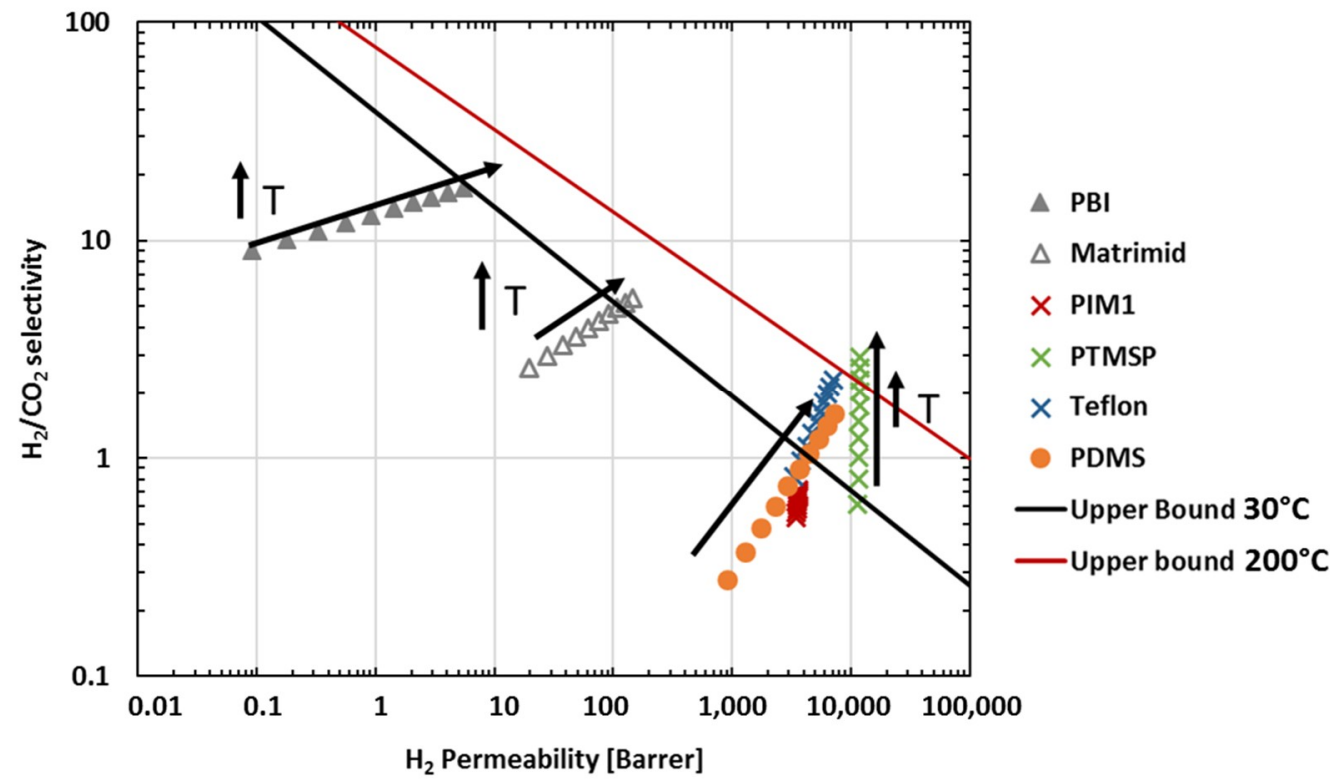

Figure 1. Influence of temperature on membrane performance (calculated from [7]) [6,8-11].

For the first Polymer of Intrinsic Microporosity, PIM-1, Budd et al. [8] showed that the $\mathrm{CO}_{2}$ permeability coefficient decreased gradually as the temperature increased, whereas the $\mathrm{H}_{2}$ permeability coefficient increased. Thus, PIM-1 also becomes slightly more $\mathrm{H}_{2}$ selective at higher temperature. Recently, Fuoco et al. [12] studied the temperature dependence of gas permeation in triptycene-based ultrapermeable PIMs, such as PIM-TMN-Trip. With increasing temperature, the permeability coefficient increased for the bulkier penetrants $\left(\mathrm{N}_{2}\right.$ and $\left.\mathrm{CH}_{4}\right)$, while for the faster penetrants $\left(\mathrm{CO}_{2}\right.$ and $\left.\mathrm{O}_{2}\right)$ it decreased and for the very small penetrants $\left(\mathrm{H}_{2}\right.$ and $\left.\mathrm{He}\right)$ it was constant. Therefore, PIM-TMNTrip became more selective to $\mathrm{H}_{2}$ at high temperature; these ultrapermeable polymers behave as microporous solids, in which the pore dimensions are rather large in comparison with the diffusing gas molecules. Such studies of the temperature and pressure dependence of transport properties are essential for understanding the behaviour of membranes over a wide range of conditions, in order to assist any consideration of industrial use.

Recently, a new type of PIM has been developed using a polymerization reaction based on the formation of the bridged bicyclic diamine called Tröger's base (TB: $6 \mathrm{H}, 12 \mathrm{H}-5,11-$ methanodibenzo $[b, f][1,5]$ diazocine), such as PIM-EA( $\left.\mathrm{Me}_{2}\right)$-TB [13] or PIM-EA( $\left.\mathrm{H}_{2}\right)$-TB [14,15] (Figure 2). PIM-EA(Me 2 TB demonstrates at ambient temperature very fast gas permeability and good selectivity, surpassing the Robeson's upper bound in the case of $\mathrm{O}_{2} / \mathrm{N}_{2}, \mathrm{H}_{2} / \mathrm{N}_{2}$ and $\mathrm{H}_{2} / \mathrm{CH}_{4}$ gas pairs [16,17]. This is due to the large diffusivity selectivity that favours transport of gas molecules of smaller kinetic diameters $\left(\mathrm{H}_{2}, \mathrm{CO}_{2}\right)$ over that of larger molecules $\left(\mathrm{N}_{2}, \mathrm{CH}_{4}\right)$.

PIM-EA $\left(\mathrm{H}_{2}\right)$-TB differs from PIM-EA( $\left(\mathrm{Me}_{2}\right)$-TB only by the absence of methyl groups at the bridgehead $(9,10)$ position of the ethanoanthracene $(E A)$ unit, which modifies its chain packing in the solid state. PIM-EA $\left(\mathrm{H}_{2}\right)$-TB presents an inter-chain distance, d-space, of $7.7 \AA$ and $32 \%$ free volume, whereas PIM-EA(Me)-TB has values of $11 \AA$ and 30\%, respectively [18]. With these differences, a higher separation performance for PIM-EA( $\left(\mathrm{H}_{2}\right)$-TB is expected. However, few papers have been published on this polymer. Bernardo et al. [15] developed thin film composite based on PIM-EA( $\left.\mathrm{H}_{2}\right)-\mathrm{TB}$ and they studied the impact of the residual casting solvent on the separation performance at $25^{\circ} \mathrm{C}$ and 
1 bar. In addition, Benito et al. [19] studied composite membranes based on a ultrathin layer of PIM-EA( $\left.\mathrm{H}_{2}\right)$-TB for $\mathrm{CO}_{2} / \mathrm{N}_{2}$ separation at $35^{\circ} \mathrm{C}$ and 3 bar.

Here we report a novel study on the permeation properties of PIM-EA $\left(\mathrm{H}_{2}\right)-\mathrm{TB}$ over a large temperature and pressure range for a series of gases $\left(\mathrm{CO}_{2}, \mathrm{H}_{2}, \mathrm{~N}_{2}\right.$ and $\left.\mathrm{CH}_{4}\right)$.

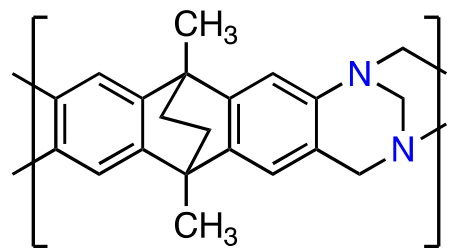

PIM-EA(Me $)$-TB

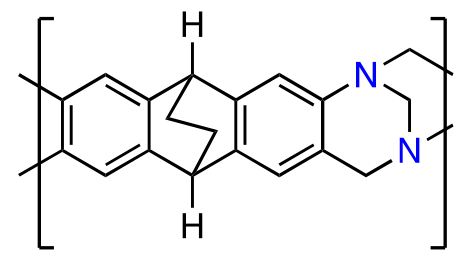

PIM-EA( $\left.\mathrm{H}_{2}\right)$-TB

Figure 2. The chemical structure of PIM-EA( $\left(\mathrm{Me}_{2}\right)-\mathrm{TB}$ and PIM-EA( $\left(\mathrm{H}_{2}\right)-\mathrm{TB}$.

\section{Experimental Section}

The detailed synthetic procedure for making PIM-EA $\left(\mathrm{H}_{2}\right)-\mathrm{TB}$ and its structural characterization are reported elsewhere [15]. Robust flat films of thickness between 130 and $200 \mu \mathrm{m}$ were cast from chloroform with their thickness determined using a digital micrometre (Mitutoyo, Kawasaki, Japan). The permeation properties were measured in a constant volume-variable pressure apparatus (Figure 3 ) using pure $\mathrm{CO}_{2}, \mathrm{~N}_{2}, \mathrm{CH}_{4}$ and $\mathrm{H}_{2}$ (Table 1) with pressures up to 20 bar (10 bar for $\mathrm{H}_{2}$ ) and temperatures up to $200^{\circ} \mathrm{C}$.

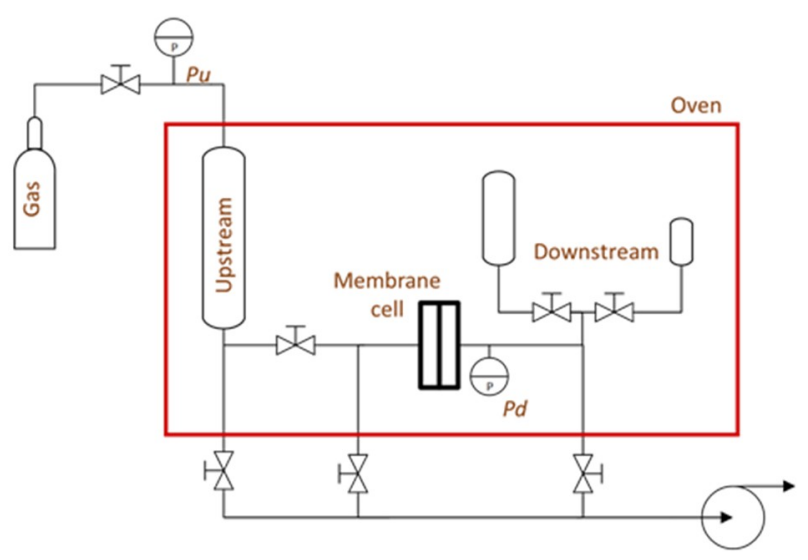

Figure 3. Constant volume-variable pressure apparatus.

Table 1. Kinetic diameter and critical temperature [20].

\begin{tabular}{ccc}
\hline Gas & Kinetic Diameter $(\boldsymbol{d})(\AA)$ & Critical Temperature $\left(T_{c}\right)(K)$ \\
\hline $\mathrm{H}_{2}$ & 2.89 & 33.2 \\
$\mathrm{~N}_{2}$ & 3.64 & 126.2 \\
$\mathrm{CH}_{4}$ & 3.8 & 190.6 \\
$\mathrm{CO}_{2}$ & 3.3 & 304.2 \\
\hline
\end{tabular}

For each measurement campaign (i.e., one gas and either variable $\mathrm{T}$ or variable $\mathrm{P}$ ), the sample was carefully treated with methanol prior to the measurement in order to start from the same ageing history. The methanol treatment consists of soaking the sample in methanol for $2 \mathrm{~h}$, drying it under ambient conditions for $20 \mathrm{~min}$ and under vacuum at $30^{\circ} \mathrm{C}$ overnight. At the end of the campaign, the gas permeability at $30^{\circ} \mathrm{C}$ and 1 bar was re-measured in order to check the absence of physical/chemical ageing. Moreover, each campaign's duration was short, carried out over a maximum of 3 days in order 
to limit physical ageing. By using this procedure, the physical ageing was minimised and had no apparent impact on the results for permeability and selectivity.

The permeability was obtained from the evolution of pressure of the downstream side (MKS Baratron 615A (Andover, MA, USA)). The permeability coefficient, $P$, was determined from the slope of the pressure vs. time curve under steady state condition. Before each experiment, the apparatus was vacuum-degassed and a leak rate determined from the pressure increase in the downstream part. Three different downstream volumes could be selected accordingly to the permeation rate of the gas.

The time lag, $\theta$, was used to determine the diffusivity coefficient $D$ (Equation (1)).

$$
D=\frac{l^{2}}{6 \theta}
$$

The solubility coefficient, $S$, for the gas in the polymer was evaluated indirectly, assuming the validity of the diffusion-solution mechanism (Equation (2)):

$$
S=\frac{P}{D}
$$

The ideal selectivity between two gas species $i$ and $j$ is the ratio of the two single gas permeabilities (Equation (3)).

$$
\alpha_{i j}=\frac{P(i)}{P(j)}
$$

\section{Results}

\subsection{Permeability}

Permeation measurements on methanol treated films of PIM-EA( $\left(\mathrm{H}_{2}\right)$-TB were carried out using pure $\mathrm{N}_{2}, \mathrm{H}_{2}, \mathrm{CO}_{2}$ and $\mathrm{CH}_{4}$ at several pressures ( 1 to 20 bar) and temperatures $\left(30^{\circ} \mathrm{C}\right.$ to $200{ }^{\circ} \mathrm{C}$ ).

Table 2 reports the results from the time lag experiment at $30^{\circ} \mathrm{C}$ and $1 \mathrm{bar}$.

Table 2. Gas permeabilities and ideal selectivities $\left(\mathrm{CO}_{2} / \mathrm{Gas}, \mathrm{H}_{2} / \mathrm{Gas}\right)$ for $\mathrm{MeOH}$ treated film

\begin{tabular}{|c|c|c|c|c|c|}
\hline \multicolumn{2}{|c|}{$30^{\circ} \mathrm{C}, 1 \mathrm{bar}$} & $\mathbf{N}_{2}$ & $\mathbf{H}_{2}$ & $\mathrm{CO}_{2}$ & $\mathrm{CH}_{4}$ \\
\hline \multirow{3}{*}{ PIM-1 [8] } & Permeability (Barrer) & 252 & 2936 & 5303 & 440 \\
\hline & Selectivity $\mathrm{CO}_{2} / \mathrm{Gas}$ & 21 & 1.8 & - & 12 \\
\hline & Selectivity $\mathrm{H}_{2} /$ Gas & 12 & - & 0.5 & 6.7 \\
\hline \multirow{3}{*}{ PIM-EA(Me $\left.{ }_{2}\right)$-TB [16] } & Permeability (Barrer) & 525 & 7760 & 7140 & 699 \\
\hline & Selectivity $\mathrm{CO}_{2} / \mathrm{Gas}$ & 13.6 & 0.9 & - & 10 \\
\hline & Selectivity $\mathrm{H}_{2} /$ Gas & 14.8 & - & 1.1 & 11 \\
\hline \multirow{4}{*}{$\begin{array}{l}\text { PIM-EA }\left(\mathrm{H}_{2}\right)-\mathrm{TB} \\
\text { (This study) }\end{array}$} & Permeability (Barrer) & 238 & 5188 & 5990 & 372 \\
\hline & $( \pm$ Error $)$ & $( \pm 3 \%)$ & $( \pm 1 \%)$ & $( \pm 1 \%)$ & $( \pm 3 \%)$ \\
\hline & Selectivity $\mathrm{CO}_{2} / \mathrm{Gas}$ & 25 & 1 & - & 16 \\
\hline & Selectivity $\mathrm{H}_{2} / \mathrm{Gas}$ & 22 & - & 1 & 14 \\
\hline
\end{tabular}
PIM-EA( $\left.\mathrm{H}_{2}\right)$-TB at $30{ }^{\circ} \mathrm{C}, 1$ bar (Errors calculated by statistical analysis of repeated measurements from separately prepared films (between 3 and 5)).

PIM-EA $\left(\mathrm{H}_{2}\right)$-TB presents high $\mathrm{CO}_{2}$ and $\mathrm{H}_{2}$ permeability coefficients and good ideal selectivity over $\mathrm{N}_{2}$ and $\mathrm{CH}_{4}$. The order of gas permeabilities for PIM-EA( $\left.\mathrm{H}_{2}\right)-\mathrm{TB}$ is $\mathrm{CO}_{2}>\mathrm{H}_{2}>\mathrm{CH}_{4}>\mathrm{N}_{2}$, the same as that for PIM-1. $\mathrm{CO}_{2}$, which is the most condensable gas, is the most permeable due to the predominant role of solubility in PIMs [8]. In comparison with PIM-EA( $\left(\mathrm{Me}_{2}\right)-\mathrm{TB}$, the permeability coefficients obtained for PIM-EA $\left(\mathrm{H}_{2}\right)-\mathrm{TB}$ are lower. This can be explained by the methyl groups increasing the distance between polymer chains of PIM-EA(Me $\left(\mathrm{Me}_{2}\right)-\mathrm{TB}$, relative to PIM-EA( $\left.\mathrm{H}_{2}\right)-\mathrm{TB}$, which ensures higher free volume and, hence, higher permeability [16] but reduces selectivity. 
Figure 4 shows the Robeson plots for five gas pairs, $\mathrm{H}_{2} / \mathrm{CH}_{4}, \mathrm{H}_{2} / \mathrm{N}_{2}, \mathrm{H}_{2} / \mathrm{CO}_{2}, \mathrm{CO}_{2} / \mathrm{CH}_{4}$ and $\mathrm{CO}_{2} / \mathrm{N}_{2}$.
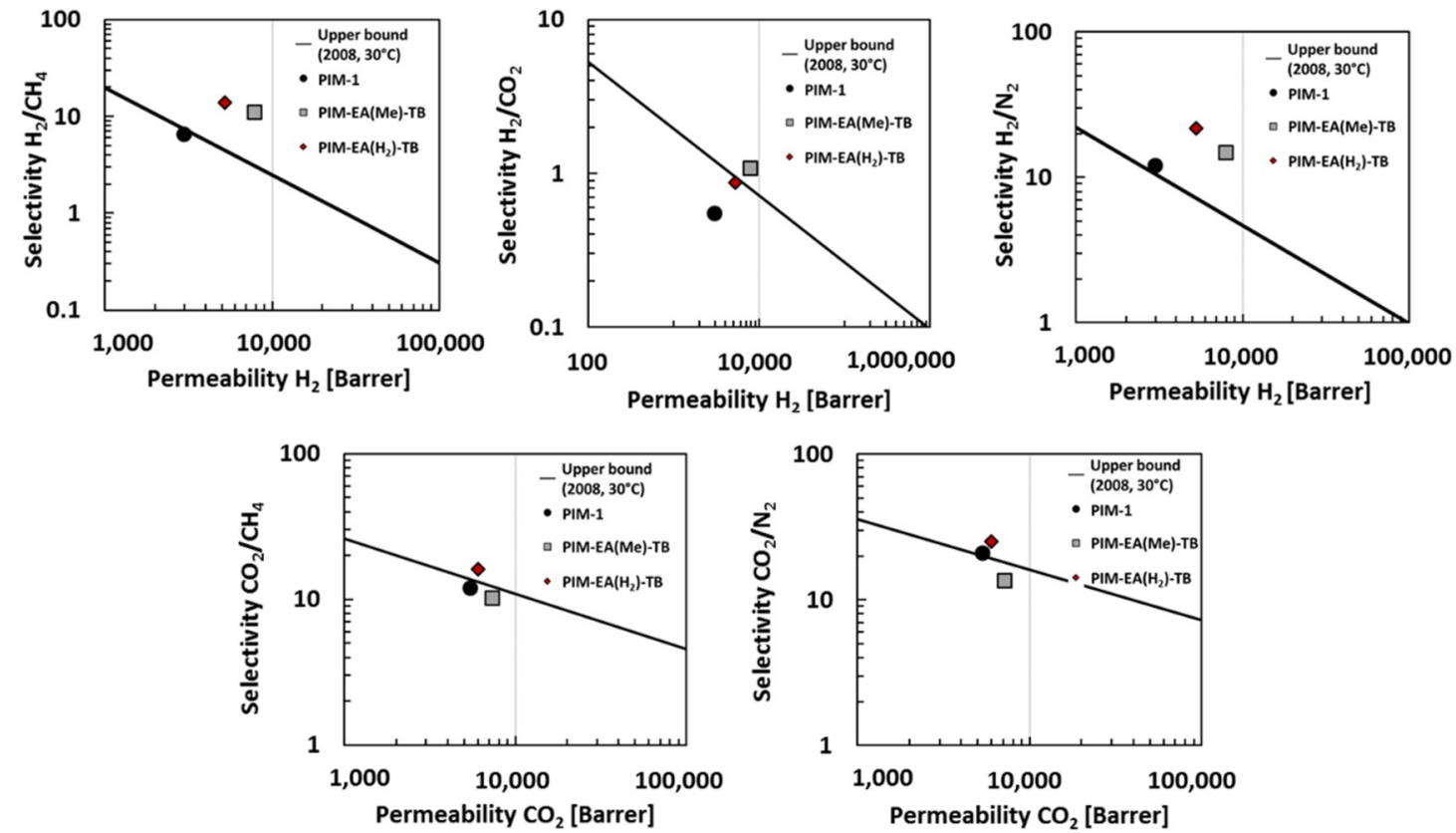

Figure 4. Robeson plots for $\mathrm{H}_{2} / \mathrm{CH}_{4}, \mathrm{H}_{2} / \mathrm{N}_{2}, \mathrm{H}_{2} / \mathrm{CO}_{2}, \mathrm{CO}_{2} / \mathrm{CH}_{4}$ and $\mathrm{CO}_{2} / \mathrm{N}_{2}$ for PIM-1 [8] (-), PIM-EA(Me $\mathrm{Me}_{2}$-TB [16] ( $\square$ ) and PIM-EA( $\left.\mathrm{H}_{2}\right)$-TB [our study] $(\diamond)$ at $30^{\circ} \mathrm{C}$ and 1 bar. The lines represents the 2008 upper bound for each gas pair [21].

As shown on Figure 4, the data for PIM-EA $\left(\mathrm{H}_{2}\right)$-TB are located above the 2008 upper bound for all five gas pairs. For $\mathrm{H}_{2} / \mathrm{CH}_{4}$ and $\mathrm{H}_{2} / \mathrm{N}_{2}$, they are clearly higher than for PIM-1 and PIM-EA(Me)-TB. This demonstrates the potential of PIM-EA $\left(\mathrm{H}_{2}\right)$-TB for industrial applications, such as carbon capture $\left(\mathrm{CO}_{2} / \mathrm{N}_{2}\right.$ mixture), natural gas sweetening and biogas treatment $\left(\mathrm{CO}_{2} / \mathrm{CH}_{4}\right.$ mixture) or hydrogen recovery $\left(\mathrm{H}_{2} / \mathrm{CH}_{4}\right.$ mixture).

\subsection{Diffusivity and Solubility Coefficients}

The gas transport in PIM-EA $\left(\mathrm{H}_{2}\right)$-TB was analysed using the solution-diffusion model (Equation (2)), to provide the diffusivity and sorption coefficients (Table 3).

Table 3. Diffusivity and solubility coefficients for $\mathrm{MeOH}$ treated film PIM-EA( $\left.\mathrm{H}_{2}\right)-\mathrm{TB}$, at $30{ }^{\circ} \mathrm{C}, 1$ bar (Errors calculated by statistical analysis of repeated measurements from separately prepared films).

\begin{tabular}{ccccc}
\hline $\mathbf{3 0}{ }^{\circ} \mathbf{C}, \mathbf{1}$ bar & $\mathbf{N}_{\mathbf{2}}$ & $\mathbf{H}_{\mathbf{2}}$ & $\mathbf{C O}_{\mathbf{2}}$ & $\mathbf{C H}_{\mathbf{4}}$ \\
\hline$D\left(10^{-7} \mathrm{~cm}^{2} / \mathrm{s}\right)$ & 9.7 & 500.0 & 8.2 & 1.3 \\
$( \pm$ Error $)$ & $( \pm 12 \%)$ & $( \pm 9 \%)$ & $( \pm 3 \%)$ & $( \pm 11 \%)$ \\
\hline$S\left(\mathrm{~cm}^{3}(\mathrm{STP}) /\left(\mathrm{cm}^{3} \cdot \mathrm{cmHg}\right)\right)$ & $3 \times 10^{-2}$ & $9 \times 10^{-3}$ & $9 \times 10^{-1}$ & $3 \times 10^{-1}$ \\
$( \pm$ Error $)$ & $( \pm 15 \%)$ & $( \pm 10 \%)$ & $( \pm 4 \%)$ & $( \pm 14 \%)$ \\
\hline
\end{tabular}

The diffusivity and solubility values of PIM-EA( $\left(\mathrm{H}_{2}\right)$-TB are similar to those of polymers from the same family (PIM-EA(Me)-TB) [16] with a very high value of $\mathrm{CO}_{2}$ solubility coefficient. This affinity towards $\mathrm{CO}_{2}$ may be enhanced by the presence of the amine groups in the TB moiety.

Diffusivity and solubility data are plotted in Figure 5 as correlations of $\log D$ versus $d^{2}$ and $\log S$ versus $T_{\mathcal{c}}$, respectively, where $d$ is the kinetic diameter and $T_{\mathcal{c}}$ is the critical temperature of the gases. 

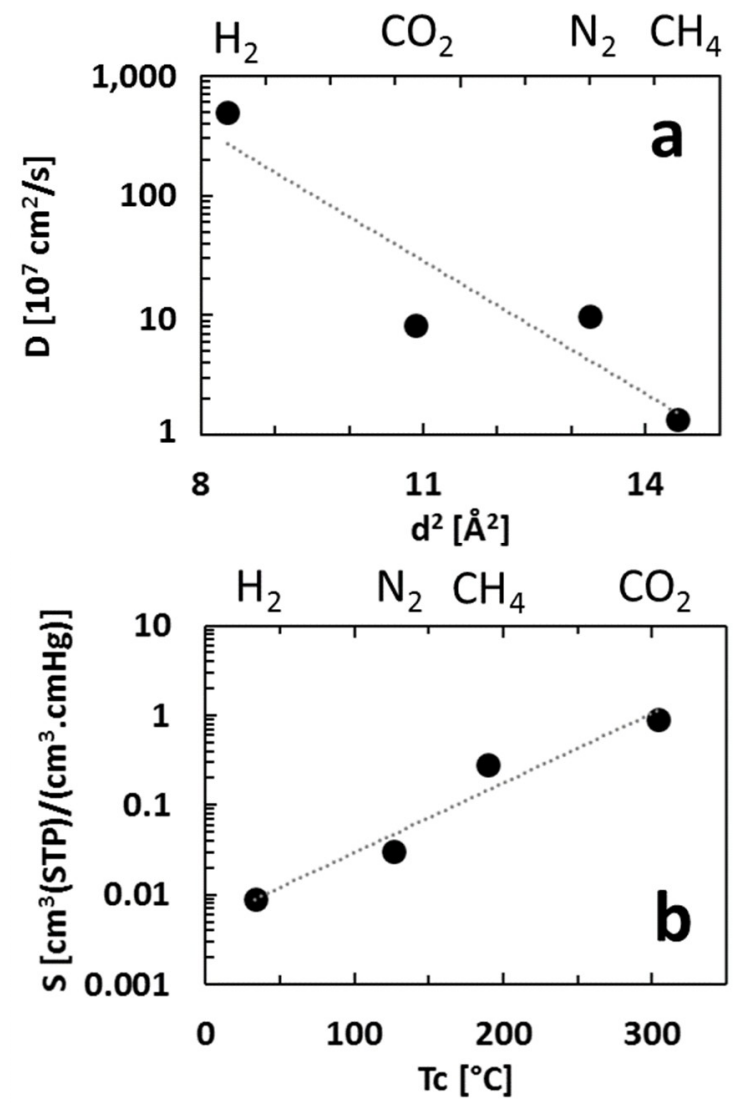

Figure 5. Diffusivity (a) and solubility (b) coefficients of PIM-EA( $\left.\mathrm{H}_{2}\right)-\mathrm{TB}$ for $\mathrm{H}_{2}, \mathrm{CO}_{2}, \mathrm{CH}_{4}$ and $\mathrm{N}_{2}$ at $30{ }^{\circ} \mathrm{C}$ and 1 bar.

Figure 5a shows that the diffusivity coefficient of PIM-EA $\left(\mathrm{H}_{2}\right)-\mathrm{TB}$ decreases with increasing molecular size of the permeate. Larger molecules interact with more segments of the polymer chains than do smaller molecules and thus the mobility selectivity always favours the passage of smaller molecules over larger ones [20]. Moreover, this decrease is large due to the glassy state of the polymer where the highly rigid polymer chains of PIM-EA $\left(\mathrm{H}_{2}\right)-\mathrm{TB}$ are essentially fixed and do not move readily to accommodate the transport of larger molecules. It is noteworthy that the value of diffusivity for $\mathrm{CO}_{2}$ is slightly lower than for $\mathrm{N}_{2}$. Generally, in polymers, the smaller molecule, that is, $\mathrm{CO}_{2}$, is expected to diffuse faster than $\mathrm{N}_{2}$, which is a larger molecule. This unusual inversion is found for polymer with high $\mathrm{CO}_{2}$ affinity $[13,17,22]$ and is caused by the specific interaction between $\mathrm{CO}_{2}$ and amine groups slowing diffusion [23].

The sorption coefficient of the gas within PIM-EA $\left(\mathrm{H}_{2}\right)$-TB increases with its critical temperature (i.e., its condensability) as is usually observed for polymers (Figure $5 b$ ).

\subsection{Effect of Pressure}

The permeability coefficients of each gas were measured as a function of upstream feed pressure. The measurements were carried out with $\mathrm{H}_{2}, \mathrm{CO}_{2}, \mathrm{CH}_{4}$ and $\mathrm{N}_{2}$ at $30^{\circ} \mathrm{C}$ and pressures up to $20 \mathrm{bar}$ (10 bar for $\mathrm{H}_{2}$ ) (Figure 6). 


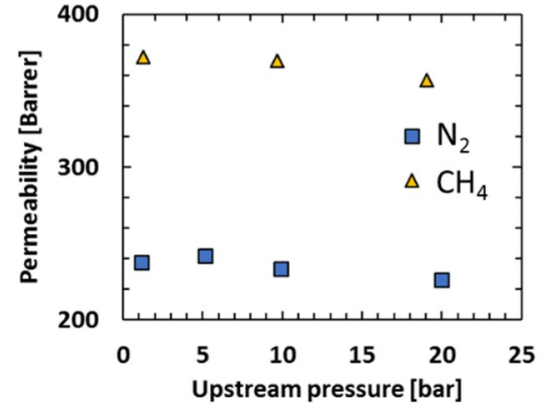

(a)

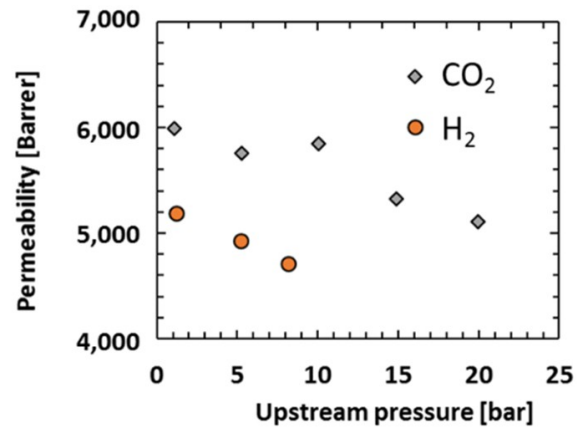

(b)

Figure 6. Permeability coefficients of PIM-EA( $\left.\mathrm{H}_{2}\right)-\mathrm{TB}$ for $\mathrm{CH}_{4}, \mathrm{~N}_{2}(\mathbf{a})$ and $\mathrm{H}_{2}, \mathrm{CO}_{2}(\mathbf{b})$ at $30{ }^{\circ} \mathrm{C}$.

The permeability of nitrogen is constant with increasing pressure while $\mathrm{CO}_{2}$ and $\mathrm{CH}_{4}$ permeabilities decrease with increasing pressure, which is classical behaviour for glassy polymers [24] and is due to the filling of Langmuir sorption sites. At higher pressures, the contribution of the Langmuir region to the overall permeability is weaker and gas permeability approaches a constant value associated with simple dissolution (Henry's law) transport. In contrast to the majority of glassy polymers, PIM-EA $\left(\mathrm{H}_{2}\right)$-TB does not exhibit the typical increase in $\mathrm{CO}_{2}$ permeability associated with "plasticization" in the high pressure range for $\mathrm{CO}_{2}$. A similar behaviour has been also noted for other polymers of intrinsic microporosity, such as PIM-1 or PIM-EA(Me)-TB [17,24,25]. However, the decrease in $\mathrm{H}_{2}$ permeability is higher than expected [25].

Despite the decrease of permeability coefficients, the ideal selectivities of PIM-EA $\left(\mathrm{H}_{2}\right)-\mathrm{TB}$ stay constant with the increase of the feed pressure (Table 4). However, it should be noted that ideal selectivity is usually not representative of behaviour at high pressure in mixed gas systems due to the interactions between different gases.

Table 4. Selectivity of PIM-EA( $\left.\mathrm{H}_{2}\right)-\mathrm{TB}$ for $\mathrm{CH}_{4}, \mathrm{~N}_{2}, \mathrm{H}_{2}, \mathrm{CO}_{2}$ at $30{ }^{\circ} \mathrm{C}$ for different pressures.

\begin{tabular}{ccccccc}
\hline Selectivity, $\mathbf{3 0}{ }^{\circ} \mathbf{C}$ & $\mathbf{H}_{\mathbf{2}} / \mathbf{C O}_{\mathbf{2}}$ & $\mathbf{H}_{\mathbf{2}} / \mathbf{N}_{\mathbf{2}}$ & $\mathbf{H}_{\mathbf{2}} / \mathbf{C H}_{\mathbf{4}}$ & $\mathbf{C O}_{\mathbf{2}} / \mathbf{N}_{\mathbf{2}}$ & $\mathbf{C O}_{\mathbf{2}} / \mathbf{C H}_{\mathbf{4}}$ & $\mathbf{C H}_{\mathbf{4}} / \mathbf{N}_{\mathbf{2}}$ \\
\hline 1 bar & 1 & 22 & 14 & 25 & 16 & 2 \\
5 bar & 1 & 20 & - & 24 & - & - \\
10 bar & 1 & 20 & 14 & 25 & 16 & 2 \\
20 bar & - & - & - & 23 & 14 & 2 \\
\hline
\end{tabular}

\subsection{Effect of Temperature}

The temperature effect on gas permeability through PIM-EA $\left(\mathrm{H}_{2}\right)-\mathrm{TB}$ was studied over a temperature range of $30-200{ }^{\circ} \mathrm{C}$ for pure gas at different pressures. The values of the permeability coefficients are summarised in the Table S1. Figure 7 shows the permeability coefficient of $\mathrm{N}_{2}, \mathrm{CO}_{2}, \mathrm{H}_{2}$ and $\mathrm{CH}_{4}$ as a function of the inverse absolute temperature at 1 bar. 


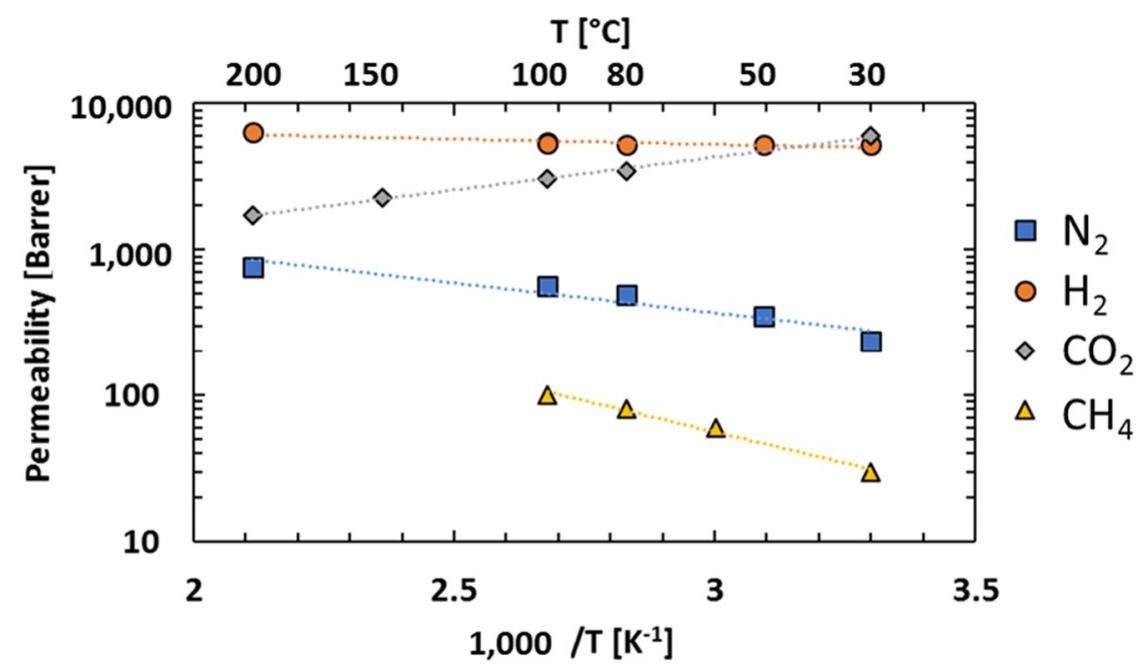

Figure 7. Permeability coefficients of $\mathrm{N}_{2}, \mathrm{CO}_{2}, \mathrm{H}_{2}$ and $\mathrm{CH}_{4}$ as a function of the inverse absolute temperature (at 1 bar) (The dotted lines represent the best curve-fits of the experimental data with Arrhenius equation).

The permeability coefficient of $\mathrm{N}_{2}, \mathrm{CH}_{4}$ and $\mathrm{H}_{2}$ increases with increasing temperature while for $\mathrm{CO}_{2}$ it decreases with increasing temperature. In order to explore the temperature dependence of the gas permeability, the data were correlated with the Arrhenius equation.

$$
P=P_{0} \exp \left(-\frac{E_{p}}{R T}\right)
$$

where $P_{0}$ is the pre-exponential factor $\left(\left(\mathrm{cm}^{3}(\mathrm{STP}) \cdot \mathrm{cm}\right) /\left(\mathrm{cm}^{2} \cdot \mathrm{s} \cdot \mathrm{cmHg}\right)\right), E_{p}$ is the activation energy of permeation $(\mathrm{J} / \mathrm{mol}), T$ is the temperature $(\mathrm{K})$ and $R$ is the ideal gas constant $(8.314 \mathrm{~kJ} /(\mathrm{mol} \cdot \mathrm{K}))$. $E_{p}$ for the transport of each gas through PIM-EA $\left(\mathrm{H}_{2}\right)$-TB were determined from the slopes $\left(-E_{P} / R\right)$ of the best curve-fits through the permeation data in Figure 7. The $E_{p}$ values at 1 bar are summarized in Table 5.

Table 5. Activation energy of gas permeation for PIM-EA( $\left.\mathrm{H}_{2}\right)$-TB, PIM-1, PIM-TMN-Trip and PTMSP.

\begin{tabular}{ccccc}
\hline \multirow{4}{*}{ Gas } & \multicolumn{4}{c}{$E_{P}(\mathbf{k J} / \mathbf{m o l})$} \\
\cline { 2 - 5 } & $\begin{array}{c}\text { PIM-EA(H }) \text { (TB } \\
\text { (This Study) }\end{array}$ & PIM-1 [26] & PIM-TMN-Trip [12] & PTMSP [26] \\
\hline $\mathrm{H}_{2}$ & 0.5 & -0.4 & -2.8 & -2.1 \\
$\mathrm{~N}_{2}$ & 8.6 & 14.3 & 4.4 & -3.5 \\
$\mathrm{CH}_{4}$ & 13.1 & 19.4 & 9.5 & -5.3 \\
$\mathrm{CO}_{2}$ & -8.6 & -1 & -7.7 & -11.7 \\
\hline
\end{tabular}

PIM-EA $\left(\mathrm{H}_{2}\right)$-TB presents high values for the activation energy of permeation for $\mathrm{N}_{2}$ and $\mathrm{CH}_{4}$, which means that the permeability coefficients depend strongly on the temperature. On the contrary, for the smaller gases, such as $\mathrm{H}_{2}, E_{P}$ is close to zero as the dependence on temperature is much weaker. For $\mathrm{CO}_{2}$, the activation energy of permeation is negative. This behaviour is routinely observed for microporous solids, such as PIM-1, PIM-TMN-Trip and PTMSP, in which the pore dimensions are relatively large in comparison with the diffusing gas molecules [11].

Since the gas transport in a microporous membrane is based on a solution-diffusion mechanism, the impact of temperature on the permeation can be better understood when looking at diffusion and solubility individually. The activation energy of permeation can be represented as the sum of the activation energies of diffusion, $E_{D}$ and sorption $\Delta H_{s}$. Table 6 lists the activation energies of gas permeation and diffusion as well as the enthalpy of sorption of all the gases in PIM-EA( $\left(\mathrm{H}_{2}\right)-\mathrm{TB}$. For all 
the gases at 1 bar, the activation energy of diffusion, $E_{D}$, is positive, which means that the diffusivity increases with the temperature, which is expected as the main effect of increasing the temperature is an increase of molecular vibrations which facilitates diffusion. In contrary, the sorption enthalpy, $\Delta H_{S}$, is negative as expected since the sorption is an exothermic process.

Table 6. Activation energies for gas permeation $\left(E_{p}\right)$, for diffusion $\left(E_{d}\right)$ and for sorption $\left(\Delta H_{s}\right)$ of PIM-EA( $\left(\mathrm{H}_{2}\right)$-TB for $\mathrm{N}_{2}, \mathrm{CO}_{2}, \mathrm{H}_{2}$ and $\mathrm{CH}_{4}$ at 1 bar.

\begin{tabular}{cccc}
\hline $\mathbf{1}$ bar & $\boldsymbol{E}_{\boldsymbol{P}}(\mathbf{k J} / \mathbf{m o l})$ & $\boldsymbol{E}_{\boldsymbol{D}}(\mathbf{k J} / \mathbf{m o l})$ & $\boldsymbol{\Delta} \boldsymbol{H}_{\boldsymbol{s}}(\mathbf{k J} / \mathbf{m o l})$ \\
\hline $\mathrm{CO}_{2}$ & -8.6 & 8.1 & -16.7 \\
$\mathrm{~N}_{2}$ & 8.6 & 18.5 & -9.9 \\
$\mathrm{H}_{2}$ & 0.5 & 5.2 & -4.6 \\
$\mathrm{CH}_{4}$ & 13.1 & 17.9 & -4.8 \\
\hline
\end{tabular}

For $\mathrm{CH}_{4}, \mathrm{~N}_{2}$ and $\mathrm{H}_{2}$, the absolute value of $E_{D}$ is greater than $\Delta H_{s}$ and so the energy of activation $E_{p}$ is positive, which means that diffusion rather than sorption dominates the response of permeation to temperature. For $\mathrm{CO}_{2}$, the absolute value of $E_{D}$ is smaller than $\Delta H_{s}$, which induces a negative activation energy $E_{P}$. The $\mathrm{CO}_{2}$ transport is mainly influenced by the gas solubility, which is characteristic of microporous polymer, with similar results being found for PIM-1 and PTMSP [5,8,11].

Based upon these effects, the increase of temperature improves $\mathrm{H}_{2} / \mathrm{CO}_{2}$ selectivity modestly moving the data for PIM-EA( $\left(\mathrm{H}_{2}\right)$-TB close to the $200{ }^{\circ} \mathrm{C}$ upper bound (Figure 8 , however, even its enhanced high temperature selectivity $(\sim 2)$ is insufficient for viable pre-combustion application. In contrast, the selectivity for $\mathrm{CO}_{2}$ or $\mathrm{H}_{2}$ over $\mathrm{N}_{2}$ or $\mathrm{CH}_{4}$ decreases dramatically at higher temperatures suggesting that optimal performance is obtained at lower temperatures (Figure 9).

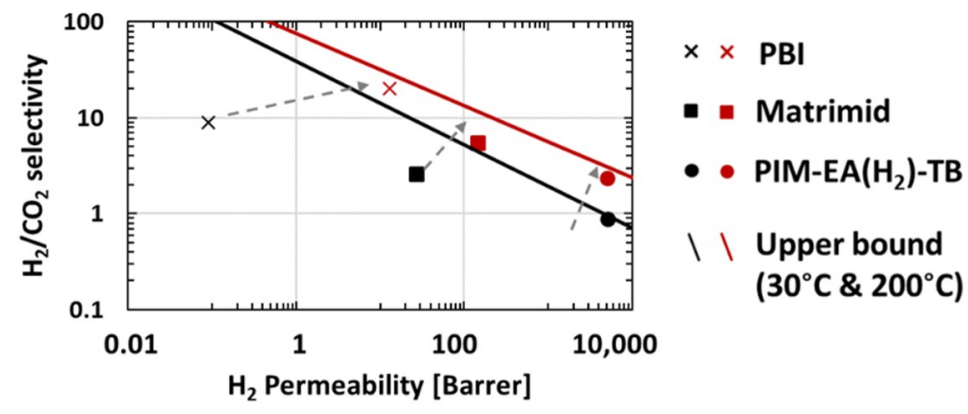

Figure 8. $\mathrm{H}_{2} / \mathrm{CO}_{2}$ separation performances of PBI (Cross), Matrimid (Square) and PIM-EA( $\left.\mathrm{H}_{2}\right)-\mathrm{TB}$ (circle) at $1 \mathrm{bar} / 30{ }^{\circ} \mathrm{C}$ (Black dot) and at $10 \mathrm{bar} / 200{ }^{\circ} \mathrm{C}$ (Red dot). Upper bound at $200{ }^{\circ} \mathrm{C}$ recalculated from [7].

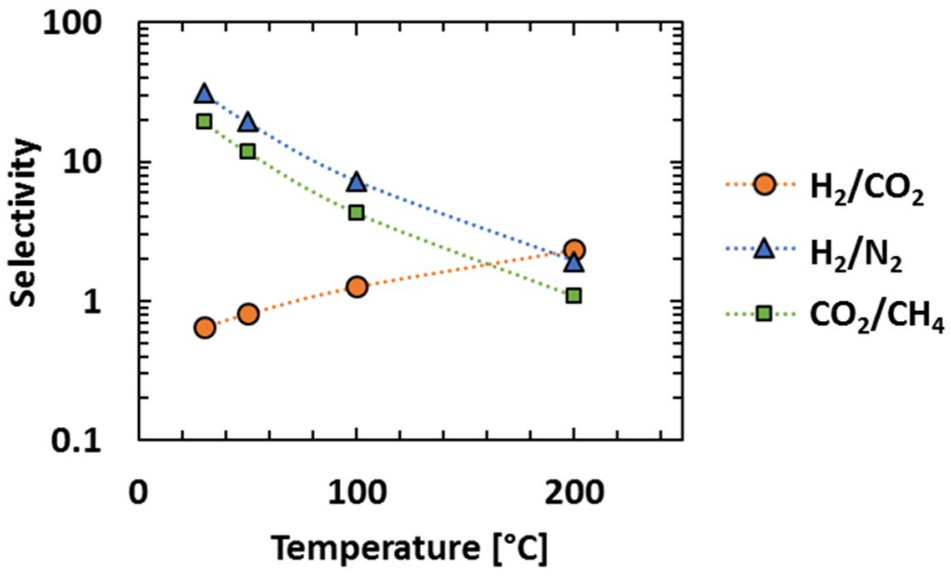

Figure 9. Selectivity of PIM-EA($\left(\mathrm{H}_{2}\right)-\mathrm{TB}$ as the function of temperature at 10 bar. 


\section{Conclusions}

Transport properties of permeability, diffusivity and solubility of PIM-EA( $\left.\mathrm{H}_{2}\right)$-TB have been determined for $\mathrm{H}_{2}, \mathrm{~N}_{2}, \mathrm{CH}_{4}$ and $\mathrm{CO}_{2}$ over a range of pressures and temperatures. This PIM presents high $\mathrm{CO}_{2}$ and $\mathrm{H}_{2}$ permeability coefficients, which allows it to have good ideal selectivity over $\mathrm{N}_{2}$. PIM-EA $\left(\mathrm{H}_{2}\right)$-TB exhibits the classical behaviour of a glassy polymer, with the decrease of diffusivity coefficient with increasing penetrant molecular size and the increase of sorption coefficient gas with increasing condensability of the permeant. However, no increase in $\mathrm{CO}_{2}$ permeability due to plasticization is noted over the range of pressure tested. The permeability coefficient of $\mathrm{N}_{2}, \mathrm{CH}_{4}$ and $\mathrm{H}_{2}$ increase with increasing temperature while for $\mathrm{CO}_{2}$ the permeability decreases with increasing temperature, which is classically observed for microporous materials. Therefore, the separation performance of PIM-EA( $\left.\mathrm{H}_{2}\right)-\mathrm{TB}$ for $\mathrm{H}_{2} / \mathrm{CO}_{2}$ is reversed at high temperature and maintained also at high pressure. This suggests that, after further development to enhance absolute selectivity of $\mathrm{H}_{2}$ over $\mathrm{CO}_{2}$, PIMs could become good candidates for membrane materials for use in pre-combustion $\mathrm{CO}_{2}$ capture. For other gas separations, better performance is obtained at lower temperatures.

Supplementary Materials: The following are available online at http:/ /www.mdpi.com/2077-0375/8/4/132/s1, Table S1: Gas permeability coefficients of $\mathrm{N}_{2}, \mathrm{CO}_{2}, \mathrm{H}_{2}$ and $\mathrm{CH}_{4}$ for temperatures between $30{ }^{\circ} \mathrm{C}$ and $200{ }^{\circ} \mathrm{C}$ and pressure between 1 bar and 20 bar.

Author Contributions: Funding acquisition, N.B.M. and M.-C.F.; Investigation, E.L., R.M.-E. and M.C.; Resources, R.M.-E. and M.C.; Supervision, M.-C.F.; Writing—original draft, E.L.; Writing—review \& editing, R.M.-E., M.C., N.B.M. and M.-C.F.

Funding: This work was financially supported by Programme Grant EP/M01486X/1 (SynFabFun) and Grant EP/R000468/1 funded by the Engineering and Physical Sciences Research Council (EPSRC).

Conflicts of Interest: The authors declare no conflict of interest.

\section{References}

1. Merkel, T.; Zhou, M.; Baker, R. Carbon dioxide capture with membranes at an IGCC power plant. J. Membr. Sci. 2012, 389, 441-450. [CrossRef]

2. Franz, J.; Scherer, V. An evaluation of $\mathrm{CO}_{2}$ and $\mathrm{H}_{2}$ selective polymeric membranes for $\mathrm{CO}_{2}$ separation in IGCC processes. J. Membr. Sci. 2010, 359, 173-183. [CrossRef]

3. Singh, R.; Berchtold, K. $\mathrm{H}_{2}$ Selective Membranes for Precombustion Carbon Capture. In Novel Materials for Carbon Dioxide Mitigation Technology; Elsevier: Amsterdam, The Netherlands, 2015; pp. 177-206.

4. Abanades, J.; Arias, B.; Lyngfelt, A.; Mattisson, T.; Wiley, D.; Li, H.; Hoc, M.; Mangano, E.; Brandani, S. Emerging $\mathrm{CO}_{2}$ capture systems. Int. J. Greenh. Gas Control 2015, 40, 126-166. [CrossRef]

5. Li, P.; Chung, T.; Paul, D. Temperature dependence of gas sorption and permeation in PIM-1. J. Membr. Sci. 2014, 450, 380-388. [CrossRef]

6. Merkel, T.; Gupta, R.; Turk, B.; Freeman, B. Mixed gas permeation of syngas components in poly(dimethylsiloxane) and poly(1-trimethysilyl-1-propyne) at elevated temperatures. J. Membr. Sci. 2001, 191, 85-94. [CrossRef]

7. Rowe, B.W.; Robeson, L.M.; Freeman, B.D.; Paul, D.R. Influence of temperature on the upper bound: Theoretical considerations and comparison with experimental results. J. Membr. Sci. 2010, 360, 58-69. [CrossRef]

8. Budd, P.M.; McKeown, N.B.; Ghanem, B.S.; Msayib, K.J.; Fritsch, D.; Starannikova, L.; Belov, N.; Sanfirova, O.; Yampolskii, Y.; Shantarovich, V. Gas permeation parameters and other physicochemical properties of a polymer of intrinsic microporosity: Polybenzodioxane PIM-1. J. Membr. Sci. 2008, 325, 851-860. [CrossRef]

9. David, O.C.; Gorri, D.; Urtiaga, A.; Ortiz, I. Mixed gas separation study for the hydrogen recovery from $\mathrm{H}_{2} / \mathrm{CO} / \mathrm{N}_{2} / \mathrm{CO}_{2}$ post combustion mixtures using a Matrimid membrane. J. Membr. Sci. 2011, 378, 359-368. [CrossRef]

10. Pesiri, D.R.; Jorgensen, B.; Dye, R.C. Thermal optimization of polybenzimidazole meniscus membranes for the separation of hydrogen, methane, and carbon dioxide. J. Membr. Sci. 2003, 218, 11-18. [CrossRef] 
11. Pinnau, I.; Toy, L.G. Gas and vapor transport properties of amorphous perfluorinated copolymer membranes based on 2,2-bistrifluoromethyl-4,5-difluoro-1,3-dioxole/tetrafluoroethylene. J. Membr. Sci. 1996, 109, 125-133. [CrossRef]

12. Fuoco, A.; Comesaña-Gándara, B.; Longo, M.; Esposito, E.; Monteleone, M.; Rose, I.; Bezzu, C.; Carta, M.; McKeown, N.; Jansen, J. Temperature Dependence of Gas Permeation and Diffusion in Triptycene-Based Ultrapermeable Polymers of Intrinsic Microporosity. ACS Appl. Mater. Interfaces 2018, 10, 36475-36482. [CrossRef] [PubMed]

13. Carta, M.; Malpass-Evans, R.; Croad, M.; Rogan, Y.; Jansen, J.C.; Bernardo, P.; Bazzarelli, F.; McKeown, N.B. An Efficient Polymer Molecular Sieve for Membrane Gas Separations. Science 2013, 339, 303-307. [CrossRef] [PubMed]

14. Hernandez, N.; Iniesta, J.; Leguey, V.M.; Armstrong, R.; Taylor, S.; Madrid, E.; Rong, Y.; Castaing, R.; Malpass-Evans, R.; Carta, M.; et al. Carbonization of polymers of intrinsic porosity to microporous heterocarbon: Capacitive pH measurements. Appl. Mater. Today 2017, 9, 136-144. [CrossRef]

15. Bernardo, P.; Scorzafave, V.; Clarizia, G.; Tocci, E.; Jansen, J.; Borgogno, A.; Malpass-Evans, R.; McKeown, N.; Carta, M.; Tasselli, F. Thin film composite membranes based on a polymer of intrinsic microporosity derived from Tröger's base: A combined experimental and computational investigation of the role of residual casting solvent. J. Membr. Sci. 2019, 569, 17-31. [CrossRef]

16. Carta, M.; Croad, M.; Malpass-Evans, R.; Jansen, J.C.; Bernardo, P.; Clarizia, G.; Friess, K.; Lanč, M.; McKeown, N. Triptycene Induced Enhancement of Membrane Gas Selectivity for Microporous Tröger's Base Polymers. Adv. Mater. 2014, 26, 3526-3531. [CrossRef] [PubMed]

17. Tocci, E.; Lorenzo, L.D.; Bernardo, P.; Clarizia, G.; Bazzarelli, F.; Mckeown, N.B.; Carta, M.; Malpass-Evans, R.; Friess, K.; Pilnáček, K.; et al. Molecular Modeling and Gas Permeation Properties of a Polymer of Intrinsic Microporosity Composed of Ethanoanthracene and Tröger's Base Units. Macromolecules 2014, 47, 7900-7916. [CrossRef]

18. Lau, C.; Konstas, K.; Doherty, C.; Carta, M.; Lasseuguette, E.; Ferrari, M.; McKeown, N.; Hill, M. Tailoring compatibility to deplasticize ageless, ultrapermeable blends for molecular sieving. In Proceedings of the ICOM 2017, San Francisco, CA, USA, 29 July-4 August 2017.

19. Benito, J.; Sánchez-Laínez, J.; Zornoza, B.; Martín, S.; Carta, M.; Malpass-Evans, R.; Téllez, C.; McKeown, N.B.; Coronas, J.; Gascón, I. Ultrathin Composite Polymeric Membranes for $\mathrm{CO}_{2} / \mathrm{N}_{2}$ separation with Minimum Thickness and High $\mathrm{CO}_{2}$ permeance. ChemSusChem 2017, 10, 4014-4017. [CrossRef]

20. Baker, R. Membrane and Technology and Applications; John Wiley \& Sons: London, UK, 2004.

21. Robeson, L. The upper bound revisited. J. Membr. Sci. 2008, 320, 390-400. [CrossRef]

22. Mason, C.R.; Maynard-Atem, L.; Heard, K.W.J.; Satilmis, B.; Budd, P.M.; Friess, K.; Lanč, M.; Bernardo, P.; Clarizia, G.; Jansen, J.C. Polymer of Intrinsic Microporosity Incorporating Thioamide Functionality: Preparation and Gas Transport Properties. Macromolecules 2014, 47, 1021-1029. [CrossRef]

23. Ghosal, K.; Chern, R.T.; Freeman, B.D.; Daly, W.H.; Negulescu, I.I. Effect of Basic Substituents on Gas Sorption and Permeation in Polysulfone. Macromolecules 1996, 29, 4360-4369. [CrossRef]

24. Li, P.; Chung, T.; Paul, D. Gas sorption and permeation in PIM-1. J. Membr. Sci. 2013, 432, 50-57. [CrossRef]

25. Swaidan, R.; Ghanem, B.; Litwiller, E.; Pinnau, I. Physical Aging, Plasticization and Their Effects on Gas Permeation in "Rigid" Polymers of Intrinsic Microporosity. Macromolecules 2015, 48, 6553-6561. [CrossRef]

26. Thomas, S.; Pinnau, I.; Du, N.; Guiver, M.D. Pure- and mixed-gas permeation properties of a microporous spirobisindane-based ladder polymer (PIM-1). J. Membr. Sci. 2009, 333, 125-131. [CrossRef]

(C) 2018 by the authors. Licensee MDPI, Basel, Switzerland. This article is an open access article distributed under the terms and conditions of the Creative Commons Attribution (CC BY) license (http://creativecommons.org/licenses/by/4.0/). 